\title{
Occurrence probability, width and number of steps of cusp precipitation for fully pulsed reconnection at the dayside magnetopause
}

Article

Published Version

Lockwood, M. and Davis, C. J. (1995) Occurrence probability, width and number of steps of cusp precipitation for fully pulsed reconnection at the dayside magnetopause. Journal of Geophysical Research, 100 (A5). pp. 7627-7640. ISSN 01480227 doi: https://doi.org/10.1029/94JA02197 Available at https://centaur.reading.ac.uk/38808/

It is advisable to refer to the publisher's version if you intend to cite from the work. See Guidance on citing.

Published version at: http://dx.doi.org/10.1029/94JA02197

To link to this article DOI: http://dx.doi.org/10.1029/94JA02197

Publisher: American Geophysical Union

All outputs in CentAUR are protected by Intellectual Property Rights law, including copyright law. Copyright and IPR is retained by the creators or other copyright holders. Terms and conditions for use of this material are defined in the End User Agreement. 


\section{CentAUR}

Central Archive at the University of Reading

Reading's research outputs online 


\title{
Occurrence probability, width and number of steps of cusp precipitation for fully pulsed reconnection at the dayside magnetopause
}

\author{
M. Lockwood ${ }^{1}$ and C. J. Davis \\ Rutherford Appleton Laboratory, Chilton, Didcot, United Kingdom
}

\begin{abstract}
We discuss the characteristics of magnetosheath plasma precipitation in the "cusp" ionosphere for when the reconnection at the dayside magnetopause takes place only in a series of pulses. It is shown that even in this special case, the low-altitude cusp precipitation is continuous, unless the intervals between the pulses are longer than observed intervals between magnetopause flux transfer event (FTE) signatures. We use FTE observation statistics to predict, for this case of entirely pulsed reconnection, the occurrence frequency, the distribution of latitudinal widths, and the number of ion dispersion steps of the cusp precipitation for a variety of locations of the reconnection site and a range of values of the local de-Hoffman Teller velocity. It is found that the cusp occurrence frequency is comparable with observed values for virtually all possible locations of the reconnection site. The distribution of cusp width is also comparable with observations and is shown to be largely dependent on the distribution of the mean reconnection rate, but pulsing the reconnection does very slightly increase the width of that distribution comparcd with the stcady state case. We conclude that neither cusp occurrence probability nor width can be used to evaluate the relative occurrence of reconnection behaviors that are entirely pulsed, pulsed but continuous and quasi-steady. We show that the best test of the relative frequency of these three types of reconnection is to survey the distribution of steps in the cusp ion dispersion characteristics.
\end{abstract}

\section{Introduction}

We present calculations of the peak occurrence probability, the latitudinal width, and the number of steps of the energy-latitude ion dispersion of cusp precipitation of magnetosheathlike plasma into the topside ionosphere. These calculations are for one limit of the "pulsating cusp" model put forward by Lockwood and Smith [1989, 1990, 1994], Smith and Lockwood [1990], Smith et al. [1992], and Cowley et al. [1991]. The limit chosen is that of entirely pulsed reconnection, in which all reconnection between a (southward directed) interplanetary magnetic field (IMF) and the geomagnetic field takes place in pulses (i.e., the reconnection rate between the pulses falls to zero). In this limit, the pulsating cusp model predicts the existence of "stepped" or "staircase" cusp ion dispersion signatures as presented by Newell and Meng [1991], Escoubet et al. [1992] and Lockwood et al. [1993a], and as explained by Lockwood and Smith [1992].

\section{The Pulsating Cusp Model}

Smith and Lockwood [1990], stress that an entirely pulsed rate variation is one limit of the general behavior of the reconnection at the dayside magnetopause: the other limit

${ }^{1}$ Also at Imperial College, London.

Copyright 1995 by the American Geophysical Union.

Paper number 94JA02197.

0148-0227/95/94JA-02197\$05.00 being steady reconnection (i.e., the reconnection rate remains constant). As yet, there is no known reason why the reconnection rate should not show a full range of variations between, and including, these two limits. However, we largely confine this paper to the entirely pulsed limit. The reason is that a great number of publications about the cusp have been based on the opposite limit, namely on the assumption that the reconnection rate is continuous or even constant. It is often argued [e.g., Newell and Sibeck, 1993] that the apparently continuous nature of cusp precipitation shows that the reconnection which gives the magnetosheath plasma access to the ionosphere is also continuous. On the other hand, Lockwood and Smith [1994] have argued that this is not the case because of the wide range of flight times of cusp ions observed at low altitudes. As discussed by Cowley et al. [1991], Lockwood and Smith [1992, 1993, 1994], Onsager et al. [1993], and Lockwood et al. [1993a], magnetosheath plasma streams across the magnetopause continuously while a field line is open. Direct evidence for this comes from the recent observations of $D$-shaped ion velocity distribution functions in the (open) low-latitude boundary layer (LLBL) [Smith and Rodgers, 1991; Gosling et al., 1990a; Fuselier et al., 1991], as was predicted by Cowley [1982]. Further evidence comes from the "stress-balance test" applied at both the dayside magnetopause [Paschmann et al., 1986; Sonnerup et al., 1990; Smith and Rodgers, 1991] and at the tail lobe boundary [Sanchez et al., 1990; Sanchez and Siscoe, 1990]. Plasma which reaches the topside ionosphere, within the spectral requirements laid down by Newell et al. [1991], is classified as "cusp." Such cusp precipitation 
persists on any one newly opened field line for an extended period of time (giving the cusp region latitudinal width as field lines convect): if that period of time exceeds any intervals of no reconnection between pulses, then a region of cusp precipitation will be continuously present, even though the reconnection is entirely pulsed. Hence a continuous cusp precipitation does not prove that the reconnection is not fully pulsed (when the reconnection only occurs within a series of pulses, between which the rate is zero).

As a brief aside, we also here note that it is not yet known whether or not the cusp precipitation is continuous in nature on the short (roughly less than $30 \mathrm{~min}$ ) timescales of pulsed reconnection discussed here. Proof of continuous precipitation cannot be obtained from satellite passes which intersect the cusp in one hemisphere for about $1-5 \mathrm{~s}$. every $90 \mathrm{~min}$. Proxy remote-sensing observations of the cffects of cusp precipitation (for example enhanced ionospheric electron temperature observed by incoherent scatter radars and broad spectra received by HF backscatter radars) do indicate that the precipitation may often be continuous - at least down to the scan time of the radars employed. In the case of incoherent scatter radars, "continuous" precipitation has been reported but using scan cycle times as large as $15 \mathrm{~min}$, for which the expected reconnection rate variations (typically of period 2-20 $\mathrm{min}$ ) of the pulsating cusp model are beyond the Nyquist limit. HF radars have employed much shorter scan cycle times of about $1.5 \mathrm{~min}$, and these radars do therefore provide evidence of continuous cusp precipitation down to these $90 \mathrm{~s}$ timescales, provided the apparent correlation of broad spectra and cusp ion precipitation [Baker et al., 1990] emerges as significant from statistical surveys of large data sets. However, it must be stressed that these observational limitations concerning the continuous nature, or otherwise, of cusp precipitation are not the point at issue here: the key point we wish to stress is that continuous cusp precipitation, were it established, would not show that the reconnection was continuous.

\section{Flux Transfer Events}

In one sense, pulses of enhanced magnetopause reconnection rate are, by definition, flux transfer events (FTEs): magnetic flux is transferred from the closed to the open field line regions (which is the process of magnetic reconnection at the dayside magnetopause) and if the rate of that reconnection is pulsed, then there is an event of enhanced flux transfer. The term FTE is, however, also used to describe a characteristic set of particle and field signatures, which were discovered near the dayside magnetopause by Russell and Elphic [1978, 1979] and Haerendel et al. [1978] and explained by them in terms of bursts of reconnection. On the basis of this explanation, these signatures were also termed FTEs. To avoid confusion between the process and the magnetopause signatures, we here reserve the term FTE for the signatures and refer to the mechanism as a "reconnection pulse" or "burst." The evidence that reconnection pulses are indeed the cause of FTE signatures is strong. FTEs originate from the low-latitude dayside magnetopause [Rijnbeek et al., 1984; Berchem and Russell, 1984; Daly et al., 1984] where observations of accelerated flows [Gosling et al., 1990b], stress-balance tests [Paschmann, 1984], mid-altitude cusp data [Phillips et al., 1993] and combined satellite/radar observations of the lowaltitude cusp [Lockwood et al., 1993a] place the reconnection
$X$ line for southward IMF. They are mainly seen when the IMF points southward [Rijnbeek et al., 1984; Berchem and Russell, 1984], the same conditions as required for lowlatitude reconnection. They are frequently accompanied by the accelerated ion flows predicted for newly opened field lines evolving away from a reconnection $X$ line [Paschmann et al., 1982] (see also discussion by Lockwood and Smith [1994]) and at their center they contain a mixture of magnetosheath and magnetospheric plasma, consistent with mixing on newly opened field lines [Thomsen et al., 1987; Farrugia et al., 1988, Rijnbeek et al., 1987].

Furthermore, theory shows that pulses of enhanced reconnection rate (along an active $X$ line of any spatial extent) will produce FTE-like signatures at the magnetopause. This was discussed conceptually by Southwood et al. [1988], was shown from two-dimensional MHD simulations by Scholer [1988, 1989] and has been derived by analytic studies of time-dependent Petschek reconnection by Semenov et al. [1991a, b; 1992a, b].

Sibeck [1992, 1993] has proposed that FTE signatures are not the fossil remnants of pulses of enhanced magnetopause reconnection rate, but rather that they are simply magnetopause motions in response to changes in the dynamic pressure of the solar wind flow. This model is conceptual, and thus far lacks the simulation or analytic derivation of the reconnection burst model. Lockwood [1991] has argued that such surface waves would produce tripolar signatures of the boundary normal field and not the characteristic bipolar signature of FTEs: furthermore, he has argued that even if Sibeck's mechanism could produce magnetopause FTE signatures, the probability of it reproducing the observed dependence on the magnetosheath field orientation (seen earlier/later in the same pass) is extremely low. Sibeck and Smith [1992] analyzed the plasma velocities in and around a much studied FTE observed by AMPTE-UKS and AMPTE-IRM [Farrugia et al., 1988; Rijnbeek et al., 1987] and found that, although in theory they could resolve between the reconnection and dynamic pressure pulse mechanisms, in fact the velocities fitted neither model well, probably because of large boundary normal flows due to compressive magnetopause motions. This would not be a problem for the reconnection burst model as compressive magnetopause motions could be superposed on the FTE signatures caused by the passing bulge in the reconnection layer, as it propagates along the (moving) magnetopause. It is, however, a problem for the pressure pulse model which explains the FTE signature precisely in terms of such boundary motions: hence for this model it is not possible to superpose additional boundary motions without disrupting the FTE signature. Smith and Owen [1992] have shown that the ion temperature anisotropy in the FTE centre is not the same as that in the magnetosheath and hence that the FTE centre is not simply when the satellites have returned briefly to the magnetosheath as a boundary surface wave passes over them, as required by the pressure pulse model. In addition, in a superposed epoch study of ISEE and AMPTE observations, Elphic et al. [1994] found that there are no static or dynamic pressure pulses in the magnetosheath which could have caused the simultaneously observed magnetopause FTEs. We conclude that the evidence does not support the idea that FTEs are generated by solar wind dynamic pressure pulses, but does support the idea that they are caused by reconnection bursts. However, we do note that Sibeck's proposed mechanism does highlight 
the need for caution when discussing FTEs, in that it is certainly possible that some boundary oscillation effects could easily be included with genuine fossil signatures of a reconnection bursts in any one FTE signature classification.

\section{The Cusp Precipitation and FTEs}

There have been a number of suggestions that cusp precipitation may result from FTEs. Particles with near zero pitch angles which cross the magnetopause along the newly opened field lines produced by a reconnection burst (i.e., along those field lines which producc the magnetopause FTE signature) will undoubtedly precipitate into the topside ionosphere. There is also no doubt that the cusp precipitation is also on newly opened field lines. This evidence was recently reviewed by Lockwood and Smith [1994]. Given that the field line velocity (the de-Hoffman Teller velocity) along the magnetopause does not, to a very good approximation, depend upon the reconnection rate [Semenov et al., 1991a, b, 1992a, b] and neither do the injected particle characteristics [Cowley, 1982; Lockwood and Smith, 1994], it will not be possible to distinguish a spectrum of precipitating cusp particles which entered as a result of a reconnection burst (i.e., in association with an FTE) from those which entered due to some more steady reconnection. A burst of enhanced reconnection rate thus does not alter the precipitation on cach newly opened field line and its evolution with time elapsed since reconnection; however, it does produce such newly opened field lines at a faster rate, giving a transient increase of the latitudinal width of the cusp. The question then simply becomes how much of the cusp precipitation is associated with FTEs (as opposed to more steady forms of reconnection)? This can equivalently be stated as what fraction of the magnetopause reconnection takes place in pulses?

The first suggestion that FTEs and cusp precipitation were related was by Menietti and Burch [1988], who found, from the spread of ion energies at a given pitch angle and time, that the field-perpendicular width of the injection region was about $1 \mathrm{R}_{\mathrm{E}}$. Because the two measured dimensions of FTEs are of about this order (the third, perpendicular to the FTE direction of motion and tangential to the magnetopause, is not known), Menietti and Burch associated cusp precipitation with FTEs. Lockwood and Smith [1994] have recently argued that this field-perpendicular width of $1 R_{E}$ corresponds to an extent of over $10 R_{E}$ along the magnetopause, because of the small boundary-normal field at the magnetopause where the field lines thread the boundary via the rotational discontinuity. In addition, there is a difference between the extent of the injection region of all the ions present at any one time and that of the majority of the ions (such as give detectable densities above the threshold of any one detector). For example, Onsager [1994] has used the model described by Onsager et al. [1993] to show that there is an $8 R_{E}$ spread in injection locations for protons between $30 \mathrm{keV}$ and $30 \mathrm{eV}$ when the model electric field input gives ionospheric convection at $1 \mathrm{~km} \mathrm{~s}^{-1}$ (his Figure 2 for $83^{\circ}$ latitude): however, although there are some ions at $30 \mathrm{keV}$, his Figure $4 a$ shows that detectable fluxes are only found at energies below $2 \mathrm{keV}$ in this case. These factors mean that the results of Menietti and Burch [1988] are consistent with the plasma gaining entry continuously along open field lines, that is, with particle injection by reconnection. The concept of continuous entry along open field lines is also verified by the range of ion energies seen at any one place and time at low altitudes [Lockwood and Smith, 1993]. Lockwood and Smith [1994] point out that the energy spread seen in the topside ionosphere on any one field line, and hence the inferred widths of the injection region (field perpendicular or along the magnetopause) do not depend upon the reconnection rate. Hence Menietti and Burch [1988] would have gained the same result, were the reconnection rate steady, entirely pulsed or anywhere between the two (continuous but pulsed).

Lockwood and Smith [1989] associated the entire cusp precipitation region in one satellite pass with an FTE, from the flows and field-aligned currents surrounding the precipitation. However, the strongest evidence for their "pulsating cusp model" comes from its prediction of the cusp ion steps. There are two points to note about the prediction of these steps. Firstly, they could, in theory, have a spatial, rather than a temporal origin [Lockwood and Smith, 1994]; the easiest case to envisage being that of two active ionospheric merging gaps (mapping to active reconnection X-line segments at the magnetopause), separated by an adiaroic segment of the open/closed boundary (mapping to a non-reconnecting segment of the magnetopause) [Lockwood, 1994; L. A. Weiss et al., Flow-aligned jets in the magnetospheric cusp: Results from the GEM pilot programme, submitted to Journal of Geophysical Research, 1994].

However, as discussed by Lockwood and Smith [1994] and Lockwood [1994] at least some of the observed steps cannot be explained as such spatial structures. The second point is that steps are only predicted by the Cowley et al. [1991] model of the ionospheric signatures of pulsed reconnection. This is because only this model allows successive patches of newly-opened flux in the ionosphere (caused by successive reconnection pulses) to be appended directly sunward of the one immediately prior to it, giving the step in the cusp ion dispersion signature. All previous models (which we term the rigid "moving-cloud" models) do not allow this: as was demonstrated by Lockwood et al. [1988], such models leave the boundary in a distorted shape and a patch of newly opened flux is only connected to its predecessor by a singular point: the probability of seeing a cusp ion step between two contiguous patches would therefore be negligible.

Lockwood and Smith [1992] used an example of a stepped ion cusp to show that, for this explanation, the reconnection must have been entirely pulsed, i.e. the cusp was one of a series of patches of newly opened flux, each being produced by a pulse of reconnection, between which there was no "background" reconnection. Lockwood [1994] has shown that the event described by Lockwood and Smith [1989] is bounded by a cusp ion step which is temporal (and not spatial) in origin: in this case, the reconnection rate was almost completely pulsed, but there was a very small background reconnection rate between the pulses. On the other hand, examples in the literature of quasi-continuous dispersion of cusp ions, without steps [e.g. Newell et al, 1991] show that the reconnection can be "steady." The word steady is placed in quotes here because Lockwood and Smith [1994] have shown that, in this context, it means that the reconnection rate varied by a factor of less than about 2 during the relevant period of about $12 \mathrm{~min}$. It is important to evaluate the frequency of these two types of reconnection rate behavior.

The purpose of this paper is to predict the occurrence frequency of the cusp precipitation and the distribution of its 
latitudinal width for the special limit of fully pulsed reconnection. This not only demonstrates the above points about the effects of different behaviours of the reconnection rate, but also provides predictions which can be matched up to statistical surveys of the cusp, as seen by satellites in the topside ionosphere. In addition, we present predictions of the distribution of the numbers of steps in the cusp ion dispersion which would be seen for purely pulsed reconnection. This last prediction will be a particularly clear test for how common pulsed magnetopause reconnection is, relative to more steady forms.

\section{Cusp Particle Entry Across the Magnetopause}

Figure 1 demonstrates the principles of cusp ion injection. In this diagram, the reconnection site $(X)$ is deliberately placed away from the subsolar magnetopause to stress that this location is not assumed. We consider field-aligned distances $d$ from a satellite $(S)$ in the topside ionosphere to the reconnection site which range from 8 to $20 R_{E}$. Using the Tsyganenko T87 model of the magnetic field for $K p$ of 6 and equinox conditions [Tsyganenko, 1987], we find that for $d=$ $d_{c}=8 R_{E}$, the reconnection site would be near the magnetic cusp in the same hemisphere as the satellite. (In the example of Figure 1, the satellite $S$ is in the northern hemisphere, and hence the local magnetic cusp is $\mathrm{CN}$ ). For $d=14 R_{E}$ the reconnection site would be close to the equatorial dayside magnetopause and for $d=20 R_{E}$ it would be at the magnetic cusp in the opposite hemisphere (CS). Hence, by this choice for a range of $d$, we consider all possible latitudes of dayside reconnection sites, as proposed for antiparallel field reconnection by Crooker [1979]. As discussed in the intro-

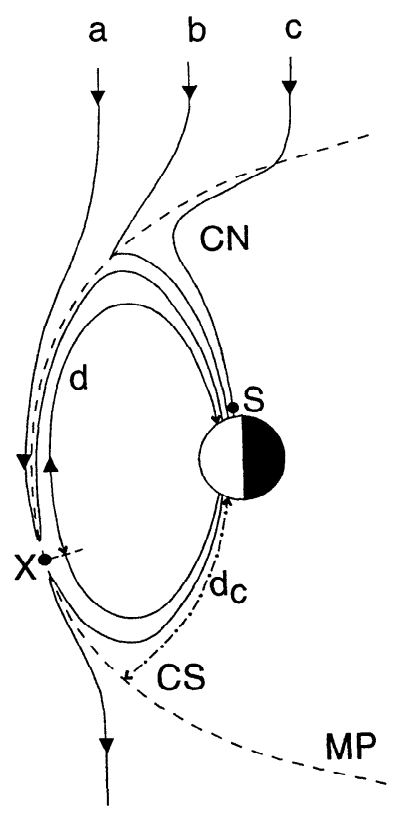

Figure 1. Schematic diagram of magnetopause reconnection during southward interplanetary magnetic field (IMF). The dashed line is the magnetopause (MP) and the magnetic cusps in the northern and southern hemispheres are marked $\mathrm{CN}$ and CS, respectively. The reconnection $X$ line is at $X$, a field-aligned distance $d$ from a satellite $S$, shown here in the northern hemisphere ionosphere, at a distance $d_{c}$ from $\mathrm{CN}$. duction, the observational evidence at the magnetopause tends to support the concept of subsolar, rather than antiparallel reconnection (the two being the same only for the special case of purely southward IMF). In addition, numerical MHD simulations tend to show subsolar reconnection [Fedder et al., 1991]. In this paper, however, we cover the full range of possible reconnection sites predicted by Crooker [1979].

As described in the previous section and by Lockwood and Smith [1994], the observational evidence (from the magnetopause, middle altitudes and low altitudes) reveals that once a field line is open, magnetosheath plasma streams continuously along it as it evolves into the tail under the joint action of magnetic tension and then magnetosheath flow. The ions precipitate down the field line at a speed such that it convects considerable distances during their time of flight. Electron fluxes are influenced by the more massive ions, so as to maintain the observed quasi-neutrality of the cusp [Burch, 1985]. Lockwood and Smith [1993, 1994], Onsager et al. [1994], and Onsager [1994] have demonstrated that plasma is injected across the boundary in a range of locations (the spread of which depends on the de-Hoffman Teller velocity with which the field lines evolve over the dayside magnetopause), and hence a range of ion energies is seen at any one point in the topside ionosphere. From the pitch angle - energy [Menietti and Burch, 1988] and energy-latitude [Rosenbauer et al., 1975; Reiff et al., 1977] dispersions of cusp ions, we know that they undergo scatter-free adiabatic motion. Of the spectrum of ion energies, as observed at any one instant of time, the ions with the lowest energy $\left(\mathrm{E}_{\mathrm{ic}}\right)$ have the longest time of flight and hence were the first to be injected. This argument was used by Lockwood and Smith [1992] to calculate reconnection rate as a function of time from cusp ion precipitation and by Phillips et al. [1993] to place the reconnection site close to the subsolar magnetopause.

The models of Onsager et al. [1993] and Lockwood and Smith [1994] have clarified much confusion about how reconnection gives cusp precipitation at low altitudes. Between the $X$ line and the magnetic cusp, the magnetosheath particles are accelerated on crossing the magnetopause; after it has evolved beyond the magnetic cusp, the acceleration turns to a deceleration [Hill and Reiff, 1977]. The first opportunity for magnetosheath ions to enter the magnetosphere is at the $X$ line, when the field line is opened. Hence the longest time-of-flight ions (of energy $E_{i c}$ ) seen at low altitudes will come from there. However, because of the acceleration, there will be a minimum energy which is injected at the $X$ line, as predicted by Cowley [1982], which we will term $\left[E_{\min }\right]_{\mathrm{x}}$ and which will be discussed further below. As the field line evolves, ions continue to be injected/accelerated across the magnetopause, but when the acceleration turns to deceleration near the magnetic cusp, the minimum injected energy $E_{\min }$ decreases rapidly, and this will, after the appropriate flight time, result in ions of energy below $\left[E_{\min }\right]_{x}$ precipitating into the ionosphere. Hence the cusp precipitation can be thought of as falling into two categories. In the first, the minimum ion energy $E_{i c}$ exceeds $\left[E_{\min }\right]_{x}$ : in this case the ions of encrgy $E_{i c}$ come from the $X$ line whereas higher energy ions seen simultaneously have come from higher magnetic latitudes closer to the magnetic cusp. This half of the cusp precipitation lies closer to the reconnection merging gap than the second half in which $E_{i c}$ 
$<\left[E_{\min }\right]_{x}$. In this second half, the ions of energy $E_{i c}$ no longer come from the $X$ line (and therefore no ions any longer come from the $X$ line), but the full spectrum comes from a more limited, but still extended, region at higher magnetic latitudes.

We here discuss observations by satellites at low altitudes in the topside ionosphere. Because ions with larger pitch angles mirror as the magnetic field increases with decreasing altitude, only ions with near-zero pitch angle are observed. We also only consider protons, the dominant ion species in the magnetosheath and cusp.

As discussed above, and by Lockwood and Smith [1994], the ions of energy $E_{i c}$ are injected at the reconnection $X$ line, provided they exceed the minimum energy of ions injected there, $\left[E_{\min }\right]_{x}$ (i.e., the minimum field-parallel ion energy of the injected Cowley-D distribution in the (open) LLBL near the $X$ line). From the recently verified theory of Cowley [1982], the minimum injected energy of field-parallel ions is given by

$$
E_{\min }=(m / 2)\left(V_{F} \cos \theta_{s p}\right)^{2}
$$

where $m$ is the ion mass and $V_{F}$ is the de-Hoffman Teller frame velocity with which the field lines move over the magnetopause, away from the $X$ line. Equation (1) also includes the cosine factor due to the angle $\theta_{s p}$ that the field line makes with the magnetopause on the magnetospheric side of the boundary [see Lockwood and Smith, 1994]. At the $X$ line, $\cos \theta_{s p}$ is very close to unity and $\left[E_{\min }\right]_{x}$ is determined by the local de-Hoffman Teller velocity, $\left[V_{F}\right]_{x}$, as observed by Smith and Rodgers [1991]. For a typical Alfvén speed of $150 \mathrm{~km} \mathrm{~s}^{-1}$ at the reconnection $X$ line inflow region (for which $\left.\left[V_{F}\right]_{x} \approx 200 \mathrm{~km} \mathrm{~s}^{-1}\right),\left[E_{\min }\right]_{x}$ is $200 \mathrm{eV}$. Using a simple model of the evolution of a newly opened field line, Lockwood and Smith [1994] have shown that the minimum injected ion energy, $E_{\min }$, rises with $V_{\mathrm{F}}$ as the field line accelerates away from the $X$ line, and only falls below $\left[E_{\min }\right]_{x}$ when the field line is very close to the magnetic cusp, because $\theta_{s p}$ there increases to values near $90^{\circ}$.

For this paper, the important conclusion is that lower cutoff cusp ions (i.e., those with the minimum energy of the spectrum observed at any one point in the low-altitude cusp) of energy $E_{i c}>\left[E_{\min }\right]_{x}$, would have been injected at the reconnection site, a distance $d$ from the satellite. On the other hand, lower cutoff ions of energy $E_{i c}<\left[E_{\min }\right]_{x}$ were injected across the magnetopause later in the evolution of the field line, at a location close to the magnetic cusp: to a good and conservative approximation, we take all lower cutoff ions in this second category to be injected at a field-aligned distance $d_{c}$, the minimum from the satellite to the magnetopause. (Note that this conclusion about injection locations only applies to the ions of minimum energy $E_{i c}$ and not to the full spectrum of cusp ions).

We make use of a quasi-steady state cusp satellite pass, as presented in Plate 1 of Newell at al. [1991]. In this pass, the DMSP-F7 satellite detected an almost continuous energylatitude dispersion of the lower cut-off of the precipitating ion spectrum (i.e. $E_{i c}$ shows an almost continuous variation with observation time). As discussed by Lockwood and Smith [1994], this shows that the reconnection was continuous and that the reconnection rate varied by a factor of less than about 2. From the electron and ion densities and spectrum, Newell et al. [1991] define a region that they term cusp. We adopt this classification here. We do this mainly to stress that we discuss the same cusp precipitation as described by other authors. However, the conclusions we present are not dependent on the thresholds chosen to classify magnetosheathlike particle precipitation into "cleft/LLBL", cusp, "mantle" and "polar cap." The importance of using an example of a "quasi-steady" cusp, showing continuous variation of $E_{i c}$ through the cusp and into surrounding regions, is this: were the cusp to be bounded by steps of the kind discussed in the introduction, the full range of $\mathrm{E}_{\mathrm{ic}}$ would not be observed within the cusp. Hence the full range of ion times of flight within the region designated cusp would be underestimated and this would influence the results presented in the following sections.

Taking the equatorward and poleward boundaries of the region Newell et al. [1991] classify as cusp, we find that within this region the lower cutoff ion energy $E_{i c}$ decays from $E_{i c 1}$ to $E_{i c 2}$ with increasing latitude.

From those spectra with $E_{i c}>\left[E_{\min }\right]_{x}$, we derive a spread in times of flight of

$$
\begin{gathered}
d t_{1}=d(m / 2)^{1 / 2}\left\{\left[E_{\min }\right]_{\mathrm{x}}^{-1 / 2}-E_{i c l}{ }^{-1 / 2}\right\} \\
d t_{l}=d(m / 2)^{1 / 2}\left\{\left[E_{i c 2^{-1 / 2}}-E_{i c l^{-1 / 2}}\right\} \quad \text { if }\left[E_{\min }\right]_{\mathrm{x}}<E_{i c 2}\right.
\end{gathered}
$$

In the above discussion, we concluded that all lower cutoff ions of energy $E_{i c}<\left[E_{\min }\right]_{x}$ are injected close to the magnetic cusp, a distance $d_{c}$ from the satellite. We therefore obtain a minimum estimate of $d t_{2}$, the range of injection times for such ions:

$$
\begin{gathered}
d t_{2}=d_{\mathrm{c}}(\mathrm{m} / 2)^{1 / 2}\left\{E_{i c 2^{-1 / 2}}-\left[E_{\min }\right]_{x}^{-1 / 2}\right\} \\
d t_{2}=0 \text { if }\left[E_{\min }\right]_{x}<E_{i c 2}
\end{gathered}
$$

And the total range of flight times of ions in the ionospheric cusp region is

$$
d t=d t_{1}+d t_{2}+t_{c}
$$

where $t_{c}$ is the time that the field line takes to evolve from the reconnection site to the magnetic cusp: $t_{c}$ is zero if $\left[E_{\min }\right]_{x}$ $>E_{i c}$ but will generally depend on the reconnection location, relative to the magnetic cusp and on the velocity with which the field line evolves between the two. Lockwood and Smith [1994] found values for $t_{c}$ of $150 \mathrm{~s}$ and $420 \mathrm{~s}$ for an assumed subsolar reconnection site and magnetopause Alfvén speeds of 400 and $100 \mathrm{~km} \mathrm{~s}^{-1}$, respectively (see their Figure 4). We here obtain a minimum estimate for $d t$ by putting $t_{c}$ to zero: to try to estimate this delay would greatly increase the complexity of the paper. However, we note that dt could be increased by as much as $10 \mathrm{~min}$ by this neglected factor (for low magnetopause Alfvén speeds and a reconnection site greatly removed from the local magnetic cusp), although typically values would be less than this. Note that by taking this minimum $d t$ we will also make conservative (i.e., minimum) estimates of the occurrence probability and width of the cusp.

To use (2) - (4) we need estimates of the peak and minimum cut-off energies in the cusp, $E_{i c 1}$ and $E_{i c 2}$. We obtain these from the DMSP cusp pass on January 26, 1984, presented by Newell et al. [1991] and modeled by Onsager et al. [1993] using the open magnetosphere concepts 


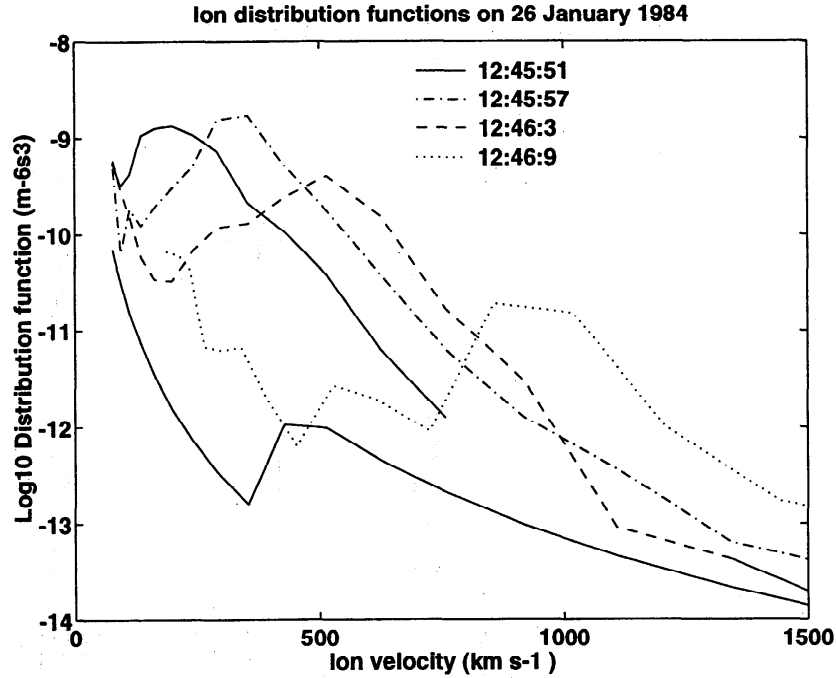

Figure 2. Field-parallel ion velocity distribution functions $f(v)$ observed by DMSP on January 26, 1984 at four times during the cusp crossing between 1245:51 and 1246:09 UT. The lower solid line is the instrument one-count level.

described in this paper. Figure 2 shows four selected fieldparallel ion velocity distribution functions, $f(v)$, as the satellite moved equatorward through the cusp, those at 1246:09 (dotted line) and 1245:51 (solid line) being at the poleward and equatorward edges of the region Newell et al. [1991] classify as cusp. The lower solid line is the one-count level. In both cases a clear low-energy cutoff in $f(v)$ can be defined. This cutoff is less clear in the other two, mid-cusp, $f(v)$ for reasons which are discussed in detail by Lockwood et al. [1994] but clearly decreases with increasing latitude. From Figure 2, we derive cutoff ion velocities which are about 930 and $70 \mathrm{~km} \mathrm{~s}^{-1}$ for 1246:09 and 1245:51, respectively, corresponding to the energies $E_{i c 1}$ and $E_{i c 2}$. Taking the

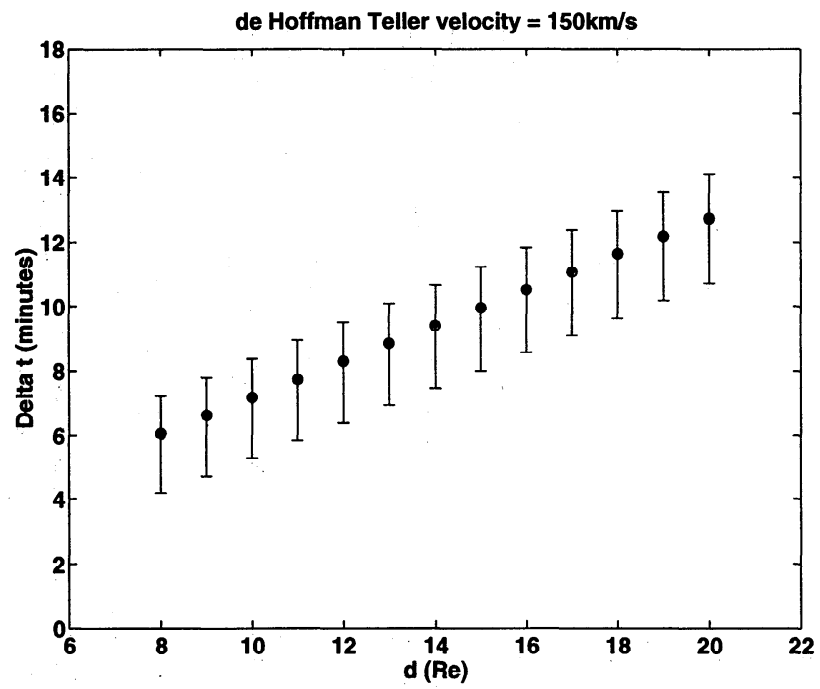

Figure 3. The interval $d t$ for which precipitation defined as cusp by Newell et al. [1991] is seen at the foot of a newly opened field line as a function of the distance $d$ from the satellite to the reconnection site. The de-Hoffman Teller velocity at the reconnection site is $V_{F}=150 \mathrm{~km} \mathrm{~s}^{-1}$.

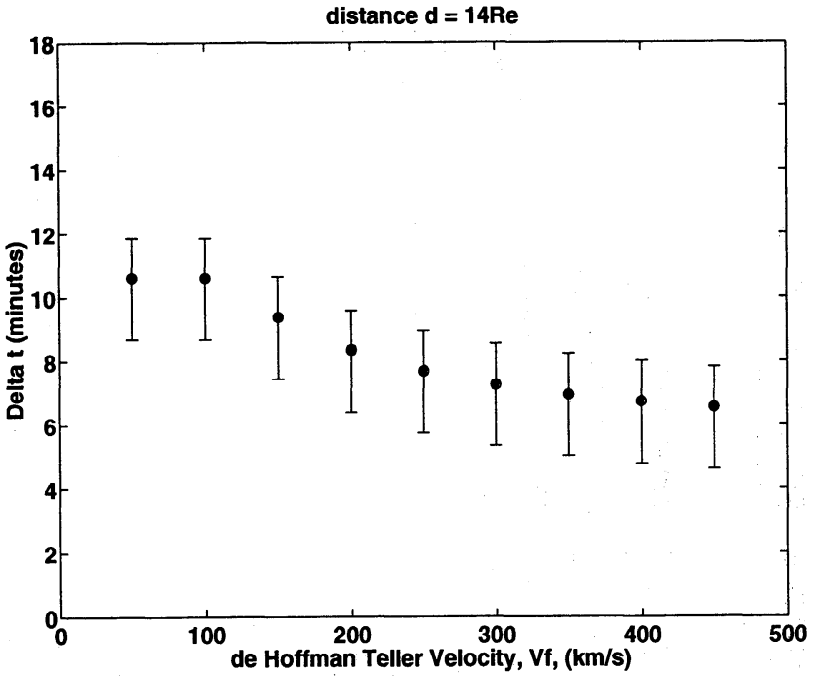

Figure 4. The variation of $d t$ with $V_{F}$, the de-Hoffman Teller velocity at a reconnection site $d=14 R_{E}$ from the satellite.

uncertainty to be the difference in the energy channels of the instrument between which the cutoff occurs, we find $E_{i c}$ is $2.6 \pm 0.5 \mathrm{keV}$ and $E_{i c 2}$ is $71 \pm 25 \mathrm{eV}$.

From (2) - (4) we can then compute $d t$ as a function of $d$ for a given $\left[E_{\min }\right]_{x} \quad\left(=m\left[V_{F}\right]_{x}^{2} / 2\right)$. The results are shown in Figure 3 for a typical de-Hoffman Teller velocity close to the $X$ line of $\left[V_{F}\right]_{x}=150 \mathrm{~km} \mathrm{~s}$ s $^{-1}$ (because henceforth all quoted de-Hoffman Teller velocities are evaluated at the $X$ line, we shall drop the subscript $x$ and only refer to the de Hoffman Teller velocity near the $X$ line as $V_{F}$ ). It can be seen that $d t$ is always greatcr than $5 \mathrm{~min}$, (note also that values in Figure 3 are underestimated by $t_{c}>0$ ). Given that a low-altitude satellite flies through the cusp in typically $1-5 \mathrm{~s}$, which is negligibly small compared with $d t$, then $d t$ is the range of injection times of ions which precipitate into the region classified as cusp by Newell et al. [1991]. Figure 3 shows that this value increases almost linearly with $d$ (this is because $E_{i c 1}$ is much greater than $\left[E_{\text {min }}\right]_{x}$, whereas $\left[E_{\min }\right]_{x}$ is only slightly greater than $E_{i c 2}$ : hence $d t_{1} \gg d t_{2}$ ) from just under 6 to over $12 \mathrm{~min}$ for the range of $d$ considered. Remember that $d=8 R_{E}$ broadly corresponds to reconnection at the local cusp, $d=14 R_{E}$ to subsolar reconnection and $d$ $=20 R_{E}$ to reconnection at the cusp of the opposite hemisphere. The error bars show the uncertainty introduced by the uncertainty in $E_{i c 1}$ and $E_{i c 2}$.

Figure 4 shows the variation of $d t$ with the assumed deHoffman Teller frame velocity $V_{F}$ for the average $d$ of $14 R_{E}$. The value of $d t$ increases with decreasing $V_{F}$ (as $d t_{1}$ increases by more than $d t_{2}$ decreases because $d>d_{c}$ ). This increase ceases at $V_{F}$ near $100 \mathrm{~km} \mathrm{~s}^{-1}$ when $\left[E_{\min }\right]_{x}$ becomes smaller than $E_{i c 2}$.

\section{Cusp Occurrence Probability}

Figures 3 and 4 show the interval $d t$ over which cusp ions cross the magnetopause and still precipitate into the topside ionosphere in the region defined as cusp. In other words, a field line will, once opened, thread the ionospheric cusp for a period $d t$. Hence for cusp precipitation to be absent at a given MLT, there must be no generation of new open flux 


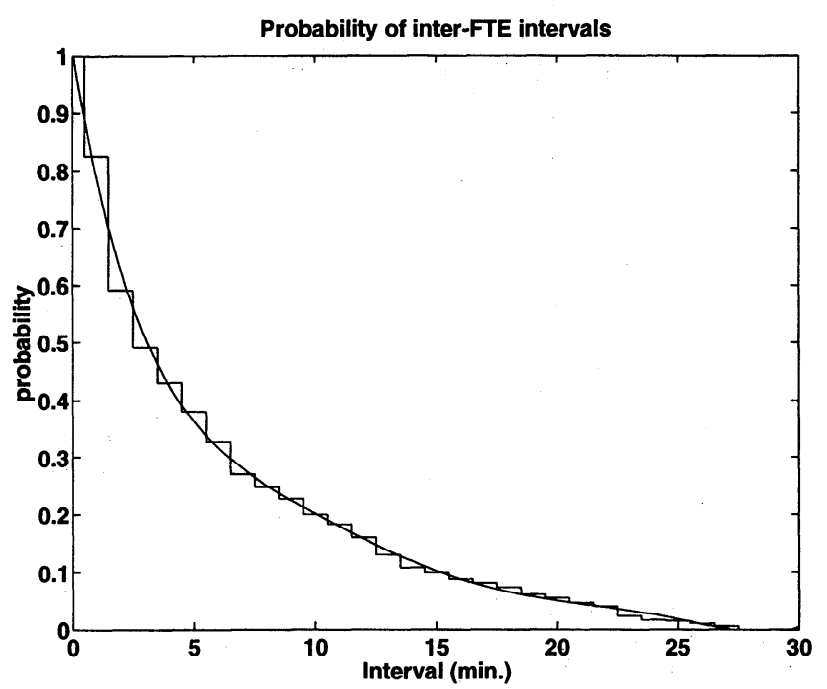

Figure 5. The cumulative probability distribution of interFTE intervals $(\tau-\Delta t)$. The histogram is the results of the statistical survey by Lockwood and Wild [1993], using 1-min bins of $(\tau-\Delta t)$, the continuous curve is a best polynomial fit used in subsequent calculations.

(i.e., no reconnection) at that MLT for a period exceeding $d t$ [Lockwood and Smith, 1994]. In this paper, we are considering the limit of entirely pulsed reconnection, and the interval between the pulses would have to exceed $d t$ for the cusp to be absent. To evaluate the probability of this we need to know the probability distribution of intervals between the reconnection pulses. If we adopt the mechanism for producing magnetopause FTE signatures which invokes reconnection pulses, we can use the statistics of FTE occurrence discussed by Lockwood and Wild [1993]. Figure 5 shows the probability (abscissa) of the interval between FTEs $(\tau-\Delta t)$, where $\tau$ is the FTE repeat period and $\Delta t$ is the event duration, exceeding the values given along the ordinate. The histogram is from the statistical survey by Lockwood and Wild and is for one-minute bins, the continuous curve is a best polynomial fit, used here in subsequent calculations. For the cusp to be absent requires $(\tau-\Delta t)>d t$ (the probability of which, $Q$, is given by Figure 5), and hence the cusp will always be present (at the relevant MLT) if $(\tau-\Delta t)$ is less than or equal to $d t$. The probability of the latter, $P$, is equal to $(1-Q)$, and hence can be evaluated from $d t$ (for a given $d$ and $V_{F}$ ) using Figure 5.

The results for $P$ are shown in Figures 6 and 7, for the same conditions as Figures 3 and 4, respectively. Figure 6 shows that for the typical $V_{F}$ of $150 \mathrm{~km} \mathrm{~s}^{-1}, P$ rises from 0.7 for $d=8 R_{E}$ (reconnection at the near cusp), to about 0.75 for subsolar reconnection $\left(d=14 R_{E}\right)$ and to about 0.8 for d= $20 R_{E}$. Figure 7 shows that for $d=14 R_{E}, P$ saturates at 0.825 for very low $V_{F}$, but is above 0.7 , even for very high $V_{F}$. Figure 8 shows contours of $P$ as a function of both $d$ and $V_{F}$. Most of these probabilities are highly comparable with the peak cusp observation frequency, as presented by Newell et al. [1989]. However, the uncertainties introduced because we do not know the value of $V_{F}$, do not allow us to use the observed peak occurrence of about $0.75 \pm 0.1$ to estimate the distance $d$. Certain combinations do, however, appear to be unlikely, for example $V_{F}$ below about $120 \mathrm{~km} \mathrm{~s}^{-1}$ with reconnection in the opposite hemisphere $\left(d>15 R_{E}\right)$ gives

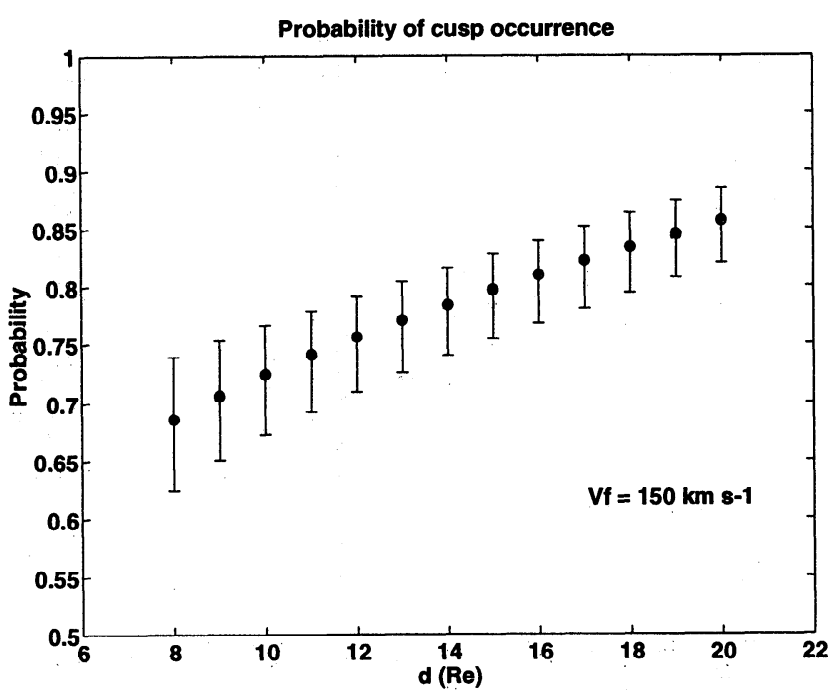

Figure 6. The occurrence probability of cusp precipitation for fully pulsed magnetopause reconnection, as a function of the distance $d$ based on the probability distribution of $(\tau-\Delta t)$ values shown in Figure 5. The de-Hoffman Teller velocity at the $X$ line is $V_{F}=150 \mathrm{~km} \mathrm{~s}^{-1}$ (as for Figure 3).

somewhat excessive $P$, whereas, very large $V_{F}$ at the near cusp ( $\mathrm{d}=8 R_{E}$ ) gives $P$ which is somewhat low (N.B. the large sheath flow speed at reconnection site near the magnetic cusp would tend to make $V_{F}$ large).

However, the key points about Figures 6-8 are these: all are based on fully pulsed reconnection, yet a wide range of values of the local de-Hoffman Teller speed, with the distance from almost any dayside reconnection site, yield cusp occurrence probabilities which compare well with observed values. The variation of cusp occurrence frequency with MLT can be explained by the azimuthal (east-west) motions of the newly opened field lines under magnetic tension, as shown by Smith et al. [1992].

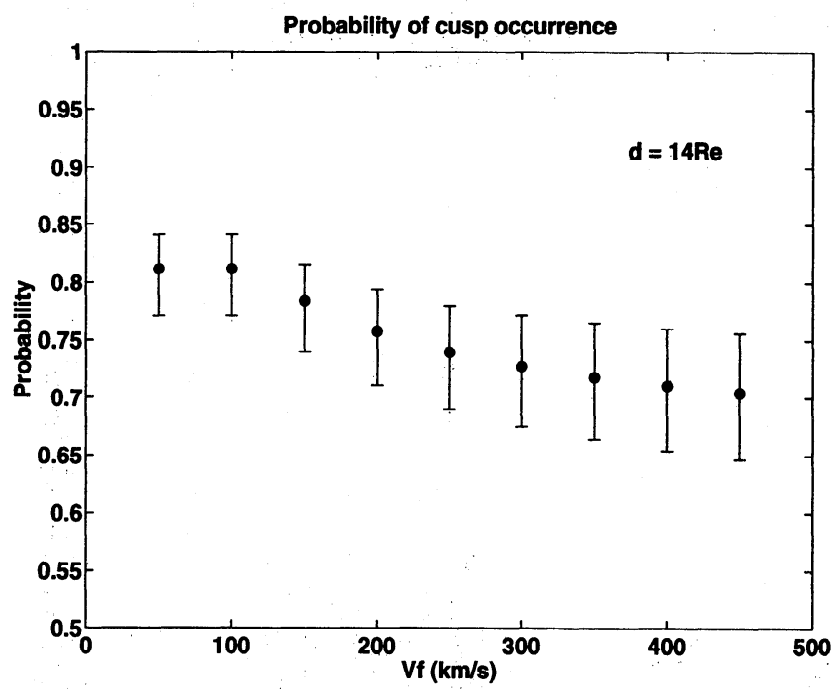

Figure 7. The occurrence probability of cusp precipitation for fully pulsed magnetopause reconnection, as a function of the $X$ line de-Hoffman Teller velocity $V_{F}$ based on the probability distribution of $(\tau-\Delta t)$ values shown in Figure 5. The distance from the satellite to the $X$ line is $d=14 R_{E}$ (as for Figure 4). 


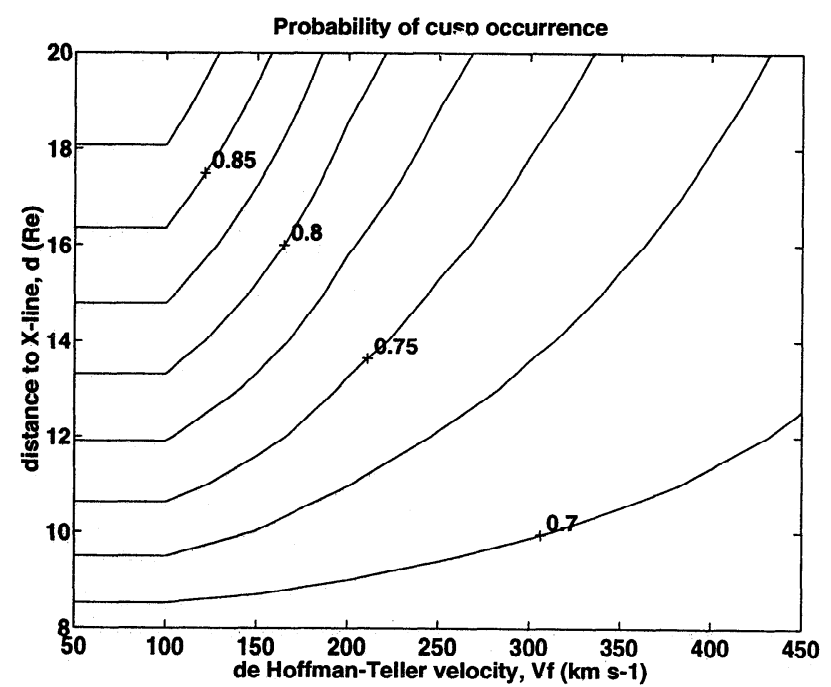

Figure 8. Contours of the occurrence probability of cusp precipitation for fully pulsed magnetopause reconnection, as a function of the $X$ line de-Hoffman Teller velocity $V_{F}$ and the distance from the satellite to the $X$ line $d$

\section{Distribution of Cusp Width}

The calculations presented in the previous two sections can also be extended to give some predictions about the distribution of "latitudinal" cusp widths, for purely pulsed reconnection. (Note that strictly the width predicted is that along the ionospheric plasma flow streamline; because that flow is generally poleward for southward IMF, we here refer to the width as latitudinal, to distinguish it from the local time extent). To do this, we must consider the probability of a pulsed reconnection rate waveform having a given period $\tau$ and (assumed square wave) pulses of length $\Delta t$, and hence of the waveform mark-to-space ratio $(\Delta t /\{\tau-\Delta t\})$.

Figure 9 shows contours of the probability density $p$ of having a given $\tau$ and $\Delta t$, again from the FTE statistics of Lockwood and Wild [1993]: $p$ is the joint probability that the FTE repeat period is between $\tau$ and $(\tau+d \tau)$ and that the FTE duration is between $\Delta t$ and $(\Delta t+d \Delta t)$ (i.e., $p$ equals $P(\tau) d \tau$ times $P(\Delta t) d \Delta t$ ), for bin sizes of $d \tau=25 \mathrm{~s}$. and $d \Delta t=$ $10 \mathrm{~s}$. This contour plot gives very similar results to the scatter diagram given in Figure 9 of Elphic [1988]. The dotted-dashed line is the limit of continuous reconnection, where the interval between pulses $(\tau-\Delta t)$ goes to zero.

Each of these reconnection pulses will produce a patch of newly-opened flux in the ionosphere and, by the Cowley et al. [1991] model, these patches will be directly appended to each other. Each boundary separating any two adjacent patches will be marked by a cusp ion jump, which will be discussed in the next section. One or more of these patches will contain precipitation which is defined as cusp and, those that do will, together, make up the full cusp region.

Magnetosheath plasma classified as cusp is seen at the ionospheric foot of any one newly opened field line for elapsed times since that field was reconnected $\left(t_{\mathrm{o}}\right)$ between $t^{\prime}$ and $\left(t^{\prime}+d t\right)$, where $t^{\prime}$ is the elapsed time after reconnection when cusp plasma first reaches the ionosphere and $d t$ is the duration of cusp precipitation on any one field line, as discussed above. In the case of steady reconnection, field lines with all $t_{\mathrm{o}}$ values in this range will be present and the cusp width would be $\left(V_{c} d t\right)$, where $V_{c}$ is the (steady) ionospheric convection speed. However, if the reconnection is fully pulsed, then some $t_{\mathrm{o}}$ values at any one instant will not be present. If a fraction $f$ of the $t_{\mathrm{o}}$ values in the range between $t^{\prime}$ and $\left(t^{\prime}+d t\right)$ are present, the total latitudinal width of the cusp, w, will be

$$
w=V_{p}^{\prime} f d t
$$

where $V_{p}^{\prime}$ is the poleward convection speed of the plasma during the reconnection pulses, in the rest frame of the ionospheric merging gap. (Because the flux transfer rate across unit length of the ionospheric open/closed boundary is $\left(V_{p}^{\prime} B_{i}\right), \quad V_{p}^{\prime}$ is directly proportional to the magnetopause reconnection rate during the pulses [see Lockwood et al., 1993b]). The fraction $f$ is the fraction of time in the interval between $t^{\prime}$ and $\left(t^{\prime}+d t\right)$ prior to each satellite pass when the reconnection was non zero. This fraction will depend upon the pulse length $\Delta t$ and period $\tau$ of the waveform of the reconnection rate variation with time, and on the phase of the satellite pass, with respect to that waveform. To calculate the probability distribution of the cusp width, w, we consider each of the reconnection rate waveforms covered by Figure 9 , for $\tau$ between 0 and $1600 \mathrm{~s}$ (in steps of $d \tau=1 \mathrm{~s}$ ) and for $\Delta t$ between 0 and $240 \mathrm{~s}$ (in steps of $d \Delta t=1 \mathrm{~s}$ ). We therefore consider a total of $1600 \times 240=384,000$ waveforms. For each we use a contour fit to Figure 9 to evaluate the probability $p^{\prime}$ of that waveform occurring. This probability is $p$ (shown in Figure 9), re-normalised to allow for the smaller bin sizes used in the model $(d \tau=d \Delta t=1 \mathrm{~s})$ than for the experimental FTE data $(d \tau=25 \mathrm{~s}, d \Delta t=10 \mathrm{~s})$. It is then necessary to consider a full range of phases of the cusp observation time, relative to that waveform. Cusp observation times are considered which are $1 \mathrm{~s}$ apart, for a complete period of the waveform, $\tau$ : the probability of each such

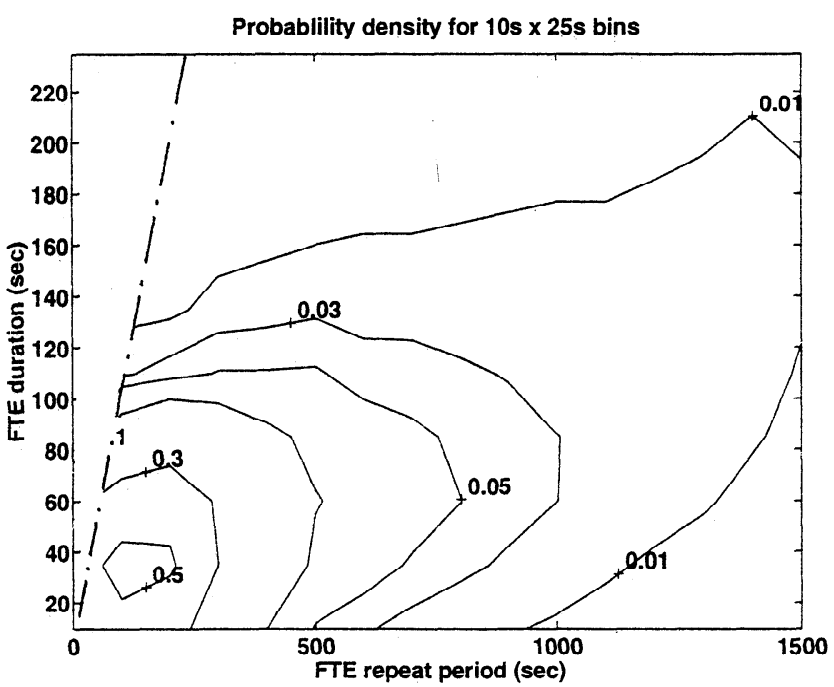

Figure 9. Contours of the probability density $p$ of inferred reconnection rate waveforms, as a function of period, $\tau$, and pulse duration, $\Delta t: p$ is the joint probability that the FTE repeat period is between $\tau$ and $(\tau+d \tau)$ and that the FTE duration is between $\Delta t$ and $(\Delta t+d \Delta t)$ (i.e. $p=P(\tau) d \tau \times$ $P(\Delta t) d \Delta t$, for bin sizes of $d \tau=25 \mathrm{~s}$. and $d \Delta t=10 \mathrm{~s}$. Contours are fitted to the magnetopause FTE statistics presented by Lockwood and Wild [1993]. The dotted-dashed curve is $\tau=\Delta t$ ( i.e. the steady reconnection limit). 
observation time is therefore $1 / \tau$. For each case, we can compute the fraction $f$ and from (5), the cusp width $w$. The probability of each case is $p^{\prime} / \tau$. The total probability of getting a cusp width of $w$ is therefore $\sum_{\mathrm{i}=1}^{\mathrm{n}}\left(p^{\prime} / \tau\right)_{i}$, where the sum is over all $n$ cases which yield the width $w$. Because there are, on average, 800 observation times per waveform, this method generated a total of $800 \times 384,000=3.072 \times 10^{8}$ cases. The results are presented here in terms of the probability that the width is between $w$ and $w+d w, P(w) d w$, for a bin size $d w$ of $20 \mathrm{~km}$.

In order to use (5) to calculate the width, we need to assume a value for $V_{p}^{\prime}$. Figure 10 shows the results for a value of $1 \mathrm{~km} \mathrm{~s}^{-1}$, that is, all the reconnection pulses are the same size, so that they cause the ionospheric feet of flux tubes to cross the open/closed boundary (in its own rest frame) at $1 \mathrm{~km} \mathrm{~s}^{-1}$. The results are shown for $d=14 R_{E}$ and $V_{F}$ of $150 \mathrm{~km} \mathrm{~s}^{-1}$ (for which Figure 3 shows that $d t \approx 8.5$ $\mathrm{min})$. In the continuous reconnection limit $(\tau-\Delta t=0 ; f=1)$, the cusp width would, by (5), be $540 \mathrm{~km}$. It can be seen that this assumption for $V_{p}^{\prime}$ leads to only a few cases where the cusp is wider than $100 \mathrm{~km}$. For southward IMF, Carbary and Meng [1988] report cusp widths of between about $1^{\circ}$ and $6^{\circ}$ (roughly corresponding to $w$ of $120-720 \mathrm{~km}$ ). Hence, with this assumed $V_{p}^{\prime}$ at least, this model of entirely pulsed reconnection does not reproduce the statistics of cusp width at all well. However, it does demonstrate how entirely-pulsed reconnection can produce extremely narrow cusps, without the convection velocity tending to zero.

Inherent in figure 10 is the assumption that the average convection velocity (in the boundary rest frame), $\left\langle V_{c}\right\rangle$, is equal to $V_{p}^{\prime} .(\Delta t / \tau)$ and $V_{p}^{\prime}$ is constant. There is no evidence that this is the case - indeed it is unlikely that all reconnection rate pulses are the same amplitude. Figure 11 presents a second calculation, for which the mean convection speed $\left\langle V_{c}\right\rangle$ is assumed constant at $0.5 \mathrm{~km} \mathrm{~s}^{-1}$, for the same $d$ and $V_{F}$ as in Figure 10. In this case, the size of the pulses

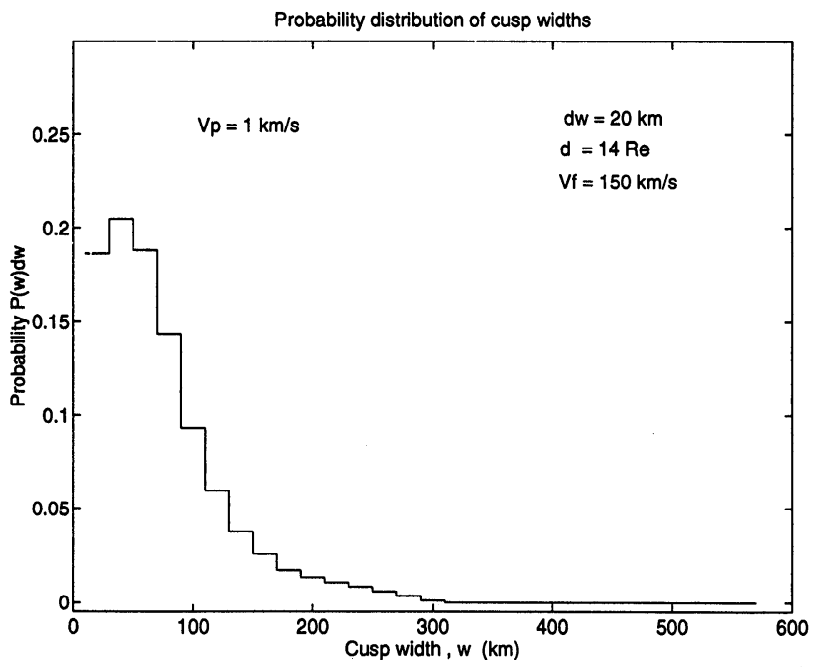

Figure 10. Probability distribution of cusp width $w P(w) d w$ for bin size $d w=20 \mathrm{~km}$. The de-Hoffman Teller velocity $V_{F}$ is $150 \mathrm{~km} \mathrm{~s}^{-1}$ at an $X$ line $d=14 R_{E}$ from the satellite. The reconnection rate in the pulses is assumed constant, such that they cause ionospheric flux transfer across the open-closed boundary at speed $V_{p}^{\prime}=1 \mathrm{~km} \mathrm{~s}^{-1}$ (in the boundary rest frame).

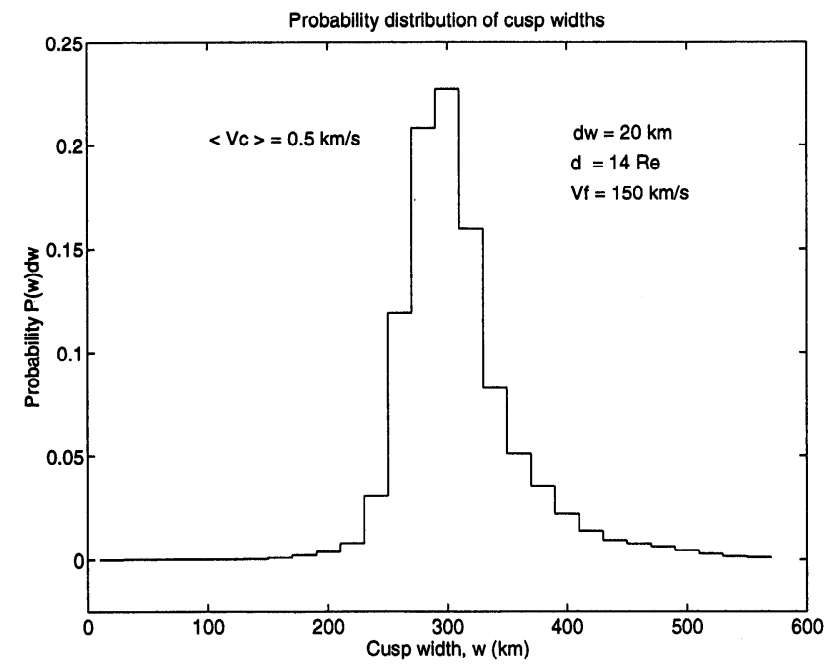

Figure 11. As for Figure 10, except that the mean (averaged over a full number of cycles of the reconnection rate variation) ionospheric flux transfer speed $\left\langle V_{c}\right\rangle$ is assumed to be constant at $0.5 \mathrm{~km} \mathrm{~s}^{-1}$.

$\left(V_{p}^{\prime}\right)$ varies with $(\Delta t / \tau)$ such that the average velocity is constant. In the steady state limit, this would yield a cusp width $w$ of $270 \mathrm{~km}$. It can be seen that for this assumption about the convection velocity, the effect of pulsing the reconnection has been to broaden the delta function distribution for steady state and produce a distribution of widths much closer to that inherent in the scatter plots of Carbary and Meng [1988].

However, it is highly unlikely that the average convection velocity would always have the value of $0.5 \mathrm{~km} \mathrm{~s}^{-1}$. Figure 12 presents a third possible assumption about the convection velocity. Here it is assumed that the average convection velocity has a Gaussian distribution, again with a mean value of $0.5 \mathrm{~km} \mathrm{~s}^{-1}$, but with a standard deviation of $0.1 \mathrm{~km} \mathrm{~s}^{-1}$, and that this distribution applies to all reconnection rate waveforms. The distribution shown in Figure 11 is now

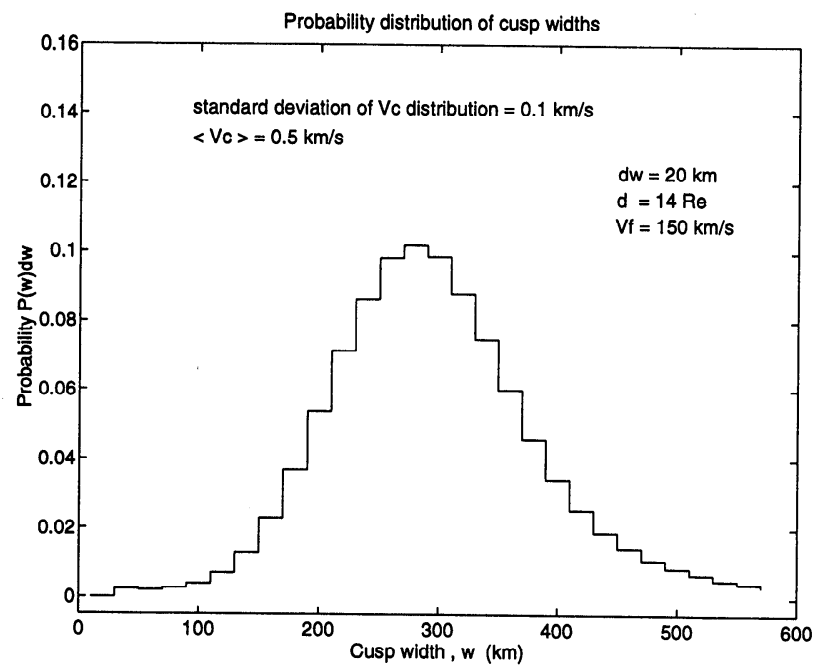

Figure 12. As for Figure 10, except that the mean ionospheric flux transfer speed, $\left\langle V_{c}\right\rangle$, is assumed to have a Gaussian distribution of mean $0.5 \mathrm{~km} \mathrm{~s}^{-1}$ and standard deviation $0.1 \mathrm{~km} \mathrm{~s}^{-1}$. 
convolved with the distribution of the convection speeds. The result is very close to the Gaussian distribution of the convection speeds and is therefore also close to the distribution that would be obtained if the reconnection were steady: there is just a slight increase in the numbers of very wide cusps and a small additional broadening of the whole distribution.

Because we do not know which type of assumption (nor indeed what values) to adopt for the convection velocity, the model does not provide a unique prediction of the distribution of cusps widths, which could be used to test for how pulsed the reconnection rate is. However, as for the occurrence probabilities discussed in the previous section, we note that the fully-pulsed model can produce distributions of cusp width which are in good agreement with observations, using plausible assumptions. We conclude that, as for occurrence probabilities, the observed distributions of cusp widths certainly are not inconsistent with the possibility that the reconnection is entirely pulsed.

Last, we note that the width $w$ is proportional to $d t$ and that, to a good approximation, $f$ does not depend on $d t$. Hence the curves shown in Figures 3 and 4 can be used to calibrate the width scale $w$ to allow for other values of $d$ and $V_{F}$. For example, using $d$ of $8 R_{E}$ (reconnection at the local magnetic cusp) for the same $V_{F}$ would multiply all the widths shown in Figures $10-12$ by a factor of $8 / 14=0.57$.

\section{Number of Steps in the Cusp Ion Dispersion}

In accumulating the statistics of the modeled cusp width, described in the previous section, it is a simple matter to record the numbers of cusp ion steps (due to the pulsed reconnection rate variation) which will be found within the cusp precipitation region. Remember, a cusp ion step is found on every boundary between regions of flux opened by successive reconnection pulses. The probability distribution of the number of such ion steps, $\mathrm{n}$, is shown by the solid line

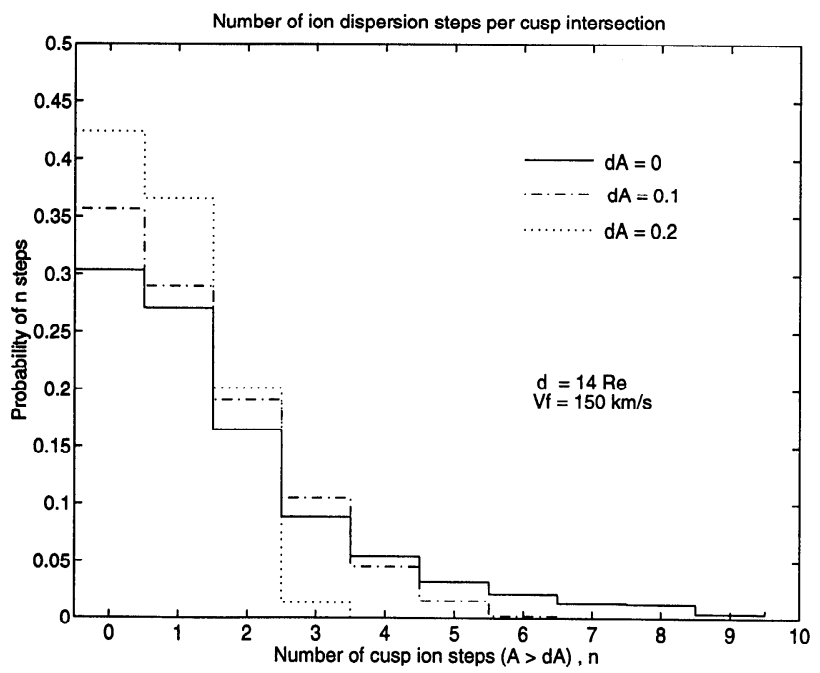

Figure 13. The probability of observing $\mathrm{n}$ ion dispersion steps within any one cusp intersection, for entirely pulsed or pulsed-but-continuous reconnection. The three histograms show the results for steps of size $A$ (on a logarithmic energy scale) exceeding a threshold $d A$ of $0,0.1$ and 0.2 (solid, dotted-dashed and dotted lines, respectively).

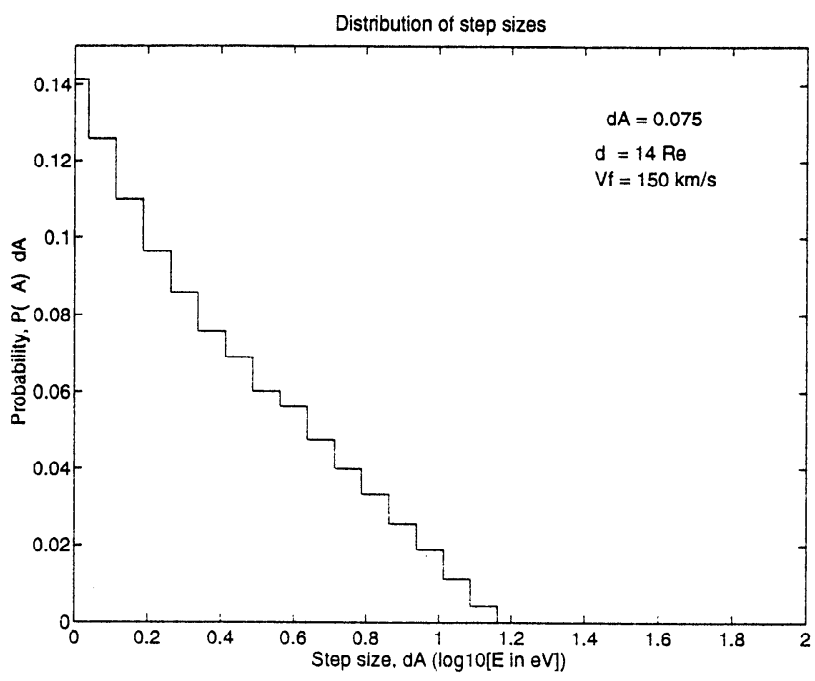

Figure 14. The distribution of step sizes $A$.

in Figure 13, again for the case of $d=14 R_{E}$ and $V_{F}=150$ $\mathrm{km} \mathrm{s}^{-1}$.

It is also a simple matter to compute the size of cach such ion step in $E_{i c}$ [see Lockwood and Smith, 1994]. Because cusp ion dispersion is almost invariably displayed on an energy-time spectrogram, using a logarithmic energy scale, it is useful to quantify the size of each step by $A$, which is the difference in $\log _{10}\left(E_{i c}\right.$ in $\left.\mathrm{eV}\right)$ between the two sides of the step.

Hence, if a given period of zero reconnection causes a step in minimum ion energy from $E_{i c a}$ down to $E_{i c b}$, then

$$
\begin{gathered}
A=\log _{10} E_{i c a}-\log _{10} \mathrm{E}_{i c b} \\
=\log _{10}\left(m d^{2} / 2 t_{a}^{2}\right)-\log _{10}\left(m d^{2} / 2 t_{b}^{2}\right) \\
=2\left\{\log _{10}\left(t_{b}\right)-\log _{10}\left(t_{a}\right)\right\}
\end{gathered}
$$

where $t_{a}$ and $t_{b}$ are the elapsed times since reconnection on either side of the step. Note (6) assumes that each pulse is reconnected at the same distance $d$, that is, the same $X$ line reactivates to give successive pulses. The implications of this are discussed later.

Those cusp crossings showing many steps (large $n$ ), each step will tend to be small. This is because in order to fit a large number of steps into the interval $d t,\left(t_{a}-t_{b}\right)$ must be small for many or all of the steps and hence, by (6), $A$ will be tend to be small. Figure 14 shows the probability distribution of step sizes, $A$ : the largest value is $A=1.13$ and the probability increases almost linearly with decreasing $A$.

Figure 13 provides a direct test for the idea that the reconnection rate is entirely pulsed in nature. This is because, if it were never so, then the distribution would be a delta function at $n=0$, apart from any spatially produced steps. We know this is not the case from the few (nonspatial) examples of stepped cusps in the literature discussed in the introduction. However, were these to be rare events (i.e., the reconnection is usually continuous), the distribution would be much closer to a delta function at $n=0$ than in Figure 13 . However, for us to apply this test, we must consider what threshold of step size, $d A$, we can resolve in observational data, because from Figure 14, this will clearly influence the number of steps found. The solid line in Figure 13 includes all steps, irrespective of their size, i.e. the threshold value of 
$A$ is zero $(d A=0)$. Figure 13 also shows the distributions for $A$ thresholds of $d A=0.1$ and $d A=0.2$. As the threshold of step size which can be detected is increased, so more cusp crossings will show fewer steps and fewer will show many steps. The differences between the distributions for different thresholds is interesting, in that the $A>d A=0.1$ case is relatively similar to the $A>d A=0$ case, whereas the $A>d A$ $=0.2$ distribution is considcrably different with only a few cases giving three steps and none giving four, and the fraction of cusps with no steps approaching 0.5 .

It should be noted that the size of the steps, as measured by $A$, will not depend on $d$. If we consider the energies $E_{i c a}$ and $E_{i c b}$ on either side of the step (relative to those for $d=14$ $R_{E}$ for the given interval of no reconnection causing the step) they would both be smaller by a factor equal to $(d$ [in $\left.R_{E} l / 14\right)^{2}$, if $d$ was less than $14 R_{E}$. However, on taking the difference of the logarithms (equation (6)), we find $A$ to be independent of $d$. Hence Figures 13 and 14 apply, independent of where the reconnection site is. It has been assumed that the site of the reconnection has not altered. Equation (6) could easily be generalised to include two different distances $\left(d_{a}\right.$ and $\left.d_{b}\right)$. This could either increase or decrease the size of $A$ (for $d_{a}<d_{b}$ and $d_{a}>d_{b}$, respectively). This would not influence the plot in Figure 13 for $d A=0$, but could change the distributions of $A$ exceeding nonzero thresholds.

Figure 13 provides ideal predictions with which to test for entirely pulsed reconnection. A survey of all steps $(d A=0)$ would not be possible from observational data as the smallest steps could not be resolved. However, compiling distributions for steps of $A>d A=0.1$ and $A>d A=0.2$ should be practical. If both these histograms were well reproduced by the observational data, then this would show that not only was the reconnection entirely pulsed, but that the location of the reconnection site was static $\left(d_{a}=d_{b}=d\right)$ and the distributions were not contaminated by a large number of spatially produced steps. Note that Figure 13 is based on a huge number of simulated cusp crossings $\left(3.072 \times 10^{8}\right)$ and more limited surveys of observational data will not exactly match these distributions. It should also be remembered that the distributions in Figure 13 are only for cusp ion steps within a region designated cusp, using the Newell et al. [1991] definition: steps on the boundary of the cusp are not included.

In addition, the survey could be repeated for different gradients of steps. Steps that are instantaneous (as far as can be detected with the instrument time resolution) show that the reconnection is entirely pulsed, with no reconnection taking place between the pulses. Lockwood and Smith [1994] have estimated that steps can be detected provided the background reconnection rate between the pulses is less than about half that within the pulses. The presence of some background reconnection rate between the pulses reduces the slope of the step. Hence repeating the survey for various thresholds of the step gradient would establish the occurrence of entirely pulsed reconnection, relative to that for large pulses (factor of 2 increases or more) over a background level.

\section{Discussion and Conclusions}

From the range of ion energies which were observed in one (quasi-steady state) cusp ion crossing, as presented by Newell et al. [1991], we have shown that the observed occurrence probability of cusp precipitation is consistent with entirely-pulsed reconnection, for reconnection sites anywhere on the dayside magnetopause and all reasonable values of the Alfvén speed at the reconnection site. However, because of uncertainties introduced by the resulting de-Hoffman Teller velocity near to the $X$ line, the observed occurrence frequency of the cusp cannot be used to estimate where the $X$ line usually is. We have demonstrated that cusp precipitation persists for a range $(d t)$ of elapsed times after reconnection which is generally larger than the intervals between reconnection bursts (as deduced from magnetopause FTE signatures), and hence entirely pulsed reconnection generally produces a continuous precipitation of cusp particles: this conclusion is independent of where on the dayside magnetopause the reconnection site is.

In computing distributions of cusp widths, a number of alternative assumptions have been adopted concerning the plasma convection. The key element in determining the distribution of widths was found to be the mean reconnection rate (equivalent to the mean ionospheric convection velocity in the rest frame of the open/closed boundary) and effects of pulsing that reconnection about the mean were found to be relatively small: the distribution is slightly skewed and is somewhat broadened if the reconnection is entirely pulsed than for when it is steady. Nevertheless, pulsed reconnection does enable the production of some very narrow cusps, which is important becausc obscrvations show that the cusp is sometimes so narrow that it is seen in just one satellite spin $(w \approx 10 \mathrm{~km})$, even when the flow is strong and wellaligned with the satellite orbit. From (5), a steady state cusp $(f=1)$ of such small width would require a convection velocity of only $V_{c}=V_{p}^{\prime} \approx 20 \mathrm{~ms}^{-1}$ for the example of $d=14$ $R_{E}, V_{F}=15 \mathrm{~km} \mathrm{~s}^{-1}(d t \approx 8.5 \mathrm{~min})$. Hence for steady state, very narrow cusps are only possible for virtually stagnant convection.

The results of Carbary and Meng [1988] contain a paradoxical result, in that they found that the cusp width decreased as the IMF became more southward. (Some caution may be required here concerning the definition of the cusp, as it is not clear that these authors used the same definition as Newell et al. [1991]). There is a wealth of observational evidence that the average dayside reconnection voltage increases with increasingly southward IMF [e.g., Cowley, 1984; Reiff and Luhmann, 1986], behavior which also emerges from global MHD simulations [e.g., Fedder et al. 1991]. An increase in the average reconnection voltage could be achieved by increasing the length of the reconnection $X$ line or by increasing the mean convection speed, $\left\langle V_{c}\right\rangle$, or both. For a steady state cusp $\left(f=1,\left\langle V_{c}\right\rangle=\right.$ $V_{p}^{\prime}$ ), therefore one would predict from (5) that the cusp width would increase with increasingly southward $B_{z}$, contrary to the observations. The entirely pulsed reconnection model offers a possible solution to this paradox. The study of magnetopause FTEs by Elphic [1988] suggests that the interval between reconnection pulses tends to increase with the mean reconnection rate (in other words, the reconnection rate within the pulses is much greater if the interval between them is large). If this is the case, then the probability of observing a narrow cusp would increase with increasing reconnection voltage. This is a different explanation of the paradox from that presented by Newell and Meng [1987]. These authors explained the reduced cusp width as, effectively, a reduction in $d t$ (see equation (5)) due to faster convec- 
tion of the field line just inside the magnetosphere when the reconnection rate is higher. However, as discussed by Cowley and Owen [1989] and Lockwood and Smith [1994], the speed with which a newly opened field line evolves from the reconnection site into the near tail, where the antisunward flow shuts off cusp precipitation to low altitudes, depends upon the magnetic tension and on the magnetosheath flow. To a very good approximation, it does not depend on the rcconnection rate: increases in the reconnection rate increase both the tangential electric field and the normal magnetic field at the magnetopause, such that the speed of field line motion along the magnetopause is approximately unaltered [Semenov et al., 1991a; b; 1992a; b]. This being the case, the interval $d t$ does not depend on reconnection rate and this does not provide an explanation of the dependence of the cusp width with IMF $B_{z}$.

The number of cusp steps provides the best test for the relative occurrence of quasi steady reconnection, continuousbut-pulsed reconnection and entirely-pulsed reconnection. For quasi-steady reconnection (where reconnection rate variations are smaller than a factor about 2 in any one interval $d t$ [Lockwood and Smith, 1994]) the number of temporal cusp ion steps in any one cusp crossing is zero. For continuousbut-pulsed reconnection (reconnection rate variations are larger than a factor of about 2) the steps are not instantaneous but their number will follow the histograms presented in Figure 13. Entirely pulsed reconnection will also give these histograms, but the steps will be instantaneous in nature (examples have been presented by Newell and Meng [1991], Escoubet et al. [1992], and Lockwood et al. [1993a]). The distributions of step numbers presented here are only for steps that are temporal, and not spatial, in origin. Hence in a survey of observations, it would be necessary to eliminate passes for which steps could be spatial in origin. The two can sometimes be distinguished, using the plasma flow criterion described by Lockwood [1994].

Acknowledgments. The authors thank W.F. Denig for provision of the DMSP ion data and instrument calibrations and M.F. Smith for discussions of this work.

The editor wishes to thank C. A. Gurgiolo and another referee for their assistance in evaluating this paper.

\section{References}

Baker, K.B., R.A. Greenwald, J.M. Ruoheniemi, J.R. Dudeney, M. Pinnock, P.T. Newell, M.E. Greenspan, and C.I. Meng, Simultaneous HF radar and DMSP observations of the cusp, Geophys. Res. Lett., 17, 1869-1872, 1990.

Berchem, J., and C. T. Russell, Flux transfer events on the magnetopause: Spatial distribution and controlling factors, $J$. Geophys. Res., 89, 6689-6703, 1984.

Burch, J. L., Quasi-neutrality in the polar cusp, Geophys. Res. Lett., 12, 469-472, 1985.

Carbary, J.F., and C.-I. Meng, Correlation of cusp width with $\mathrm{AE}(12)$ and $B z$, Planet. Space Sci., 36, 157-161, 1988.

Cowley, S. W. H., The causes of convection in the Earth's magnetosphere: A review of developments during IMS, Rev. Geophys., 20, 531-565, 1982.

Cowley, S.W.H., Solar wind control of magnetospheric convection, in Achievements of the International Magnetospheric Study, IMS, Eur. Space Agency Spec. Publ., SP-217, 1984.

Cowley, S.W.H., and C.J. Owen, A simple illustrative model of open flux tube motion over the dayside magnetopause, Planet. Space Sci., 37, 1461, 1989.
Cowley, S.W.H., M.P. Freeman, M. Lockwood, and M.F. Smith, The ionospheric signature of flux transfer events, in CLUSTER - Dayside Polar Cusp, Euro. Space Agency Spec. Publ., SP-330., 105-112, 1991.

Crooker, N. U., Dayside merging and cusp geometry, $J$. Geophys. Res., 84, 951, 1979.

Daly, P. W., M. A. Saunders, R. P. Rijnbeek, N. Sckopke, and C. T. Russell, The distribution of reconnection geometry in flux transfer events using energetic ion, plasma and magnetic data, J. Geophys. Res., 89, 3843, 1984.

Elphic, R.C., Multipoint observations of the magnetopause: Results from ISEE and AMPTE, $\Lambda d v$. Space Res., 8(9), 223-238, 1988.

Elphic, R.C., W. Baumjohann, C.A. Cattell, H. Lühr, and M. Smith, A search for upstream pressure pulses associated with flux transfer events:An AMPTE/ISEE Case study, $J$. Geophys. Res., 99, 13521-13527, 1994.

Escoubet, C.P., M.F. Smith, S.F. Fung, P.C. Anderson, R.A. Hoffman, E.M. Basinska, and J.M. Bosqued, Staircase ion signature in the polar cusp: A case study, Geophys. Res. Lett., $19,1735-1738,1992$.

Farrugia, C. J., et al., A multi-instrument study of flux transfer event structure, J. Geophys. Res., 93, 14465-14477, 1988.

Fedder, J.A., C.M. Mobarry, and J.G. Lyon, Reconnection voltage as a function of IMF clock angle, Geophys. Res. Lett., 18, 1047-1050, 1991.

Fuselier, S.A., D.M. Klumpar, and E.G. Shelley, Ion reflection and transmission during reconnection at the Earth's subsolar magnetopause, Geophys. Res. Lett., 18, 139-142, 1991.

Gosling, J.T., M.F. Thomsen, S.J. Bame, R.C. Elphic, and C.T. Russell, Cold ion beams in the low latitude boundary layer during accelerated flow events, Geophys. Res. Lett., 17, 2245-2248, 1990a.

Gosling, J.T., M.F. Thomsen, S.J. Bame, R.C. Elphic, and C.T. Russell, Plasma flow reversals at the dayside magnetopause and the origin of asymmetric polar cap convection, $J$. Geophys. Res., 95, 8073-8084. 1990b.

Haerendel, G., G. Paschmann, N. Sckopke, H. Rosenbauer, and P. C. Hedgecock, The frontside boundary layer of the magnetopause and the problem of reconnection, J. Geophys. Res., 83, 3195-3216, 1978.

Hill, T. W., and P. H. Reiff, Evidence of magnetospheric cusp proton acceleration by magnetic merging at the dayside magnetopause, J. Geophys. Res., 82, 3623-3628, 1977.

Lockwood, M., Flux Transfer Events at the dayside magnetopause: Transient reconnection or magnetosheath pressure pulses?, J. Geophys. Res., 96, 5497-5509, 1991.

Lockwood, M., Ground-based and satellite observations of the cusp: Evidence for pulsed magnetopause reconnection, in Geophysical Monograph Series, edited by B. U. O. Sonnerup, P. Song, and M. F. Thomsen, AGU, Washington, D. C., in press, 1994.

Lockwood, M., and S.W.H. Cowley, Ionospheric convection and the substorm cycle, in Proceedings of the First International Conference on Substorms (ICS-1), Kiruna 23-27 March, 1992, Eur. Space Agency Spec. Publ., SP-335, 99109, 1992.

Lockwood, M., and M.F. Smith, Low altitude signatures of the cusp and flux transfer events, Geophys. Res. Lett., 16, 879-882, 1989.

Lockwood, M., and M.F. Smith, Reply to Newell, Geophys. Res. Lett., 17, 305-306, 1990.

Lockwood, M., and M.F. Smith, The variation of reconnection rate at the dayside magnetopause and cusp ion precipitation, J. Geophys. Res., 97, 14,841-14,847, 1992.

Lockwood, M., and M.F. Smith, Comment on "Mapping the dayside ionosphere to the magnetosphere according to particle 
precipitation characteristics" by Newell and Meng, Geophys. Res. Lett., 20, 1739-1740, 1993.

Lockwood, M., and M.F. Smith, Low and middle-altitude cusp particle signatures for general magnetopause reconnection rate variations, 1, Theory, J. Geophys. Res., 99, 8531-8553, 1994.

Lockwood, M., and M.N. Wild, On the quasi-periodic nature of magnetopause flux transfer events, J. Geophys. Res., 98, 5935-5940, 1993.

Lockwood, M., S. W. H. Cowley, P. E. Sandholt, and R. P. Lepping, The ionospheric signatures of flux transfer events and solar wind dynamic pressure changes, J. Geophys. Res., 95, 17113-17135, 1990.

Lockwood, M., W.F. Denig, A.D. Farmer, V.N. Davda, S.W.H. Cowley, and H. Iühr, Ionospheric signatures of pulsed magnetic reconnection at the Earth's magnetopause, Nature, 3611 (6411), 424-428, 1993a.

Lockwood, M., J. Moen, S.W.H. Cowley, A.D. Farmer, U.P. Løvhaug, H. Lühr, and V.N. Davda, Variability of dayside convection and motions of the cusp/cleft aurora, Geophys. Res. Lett., 20, 1011-1014, 1993b.

Lockwood, M., M.F. Smith, C.J. Farrugia, and G.L. Siscoe, Ionospheric ion upwelling in the wake of flux transfer events at the dayside magnetopause, J. Geophys. Res., 93, 5641-5654, 1988.

Lockwood, M., T. G. Onsager, C. J. Davis, M. F. Smith and W. F. Denig, The characteristics of the magnetopause reconnection $\mathrm{X}$-line deduced from low-altitude satellite observations of cusp ions, Geophys. Res. Lett., 21, 2757$2760,1994$.

Menietti, J.D., and J.L. Burch, Spatial extent of the plasma injection region in the cusp-magnetosheath interface, $I$. Geophys. Res., 93, 105, 1988.

Newell, P. T., and C. I. Meng, Cusp width and $B_{z}$ : Observa tions and a conceptual model, J. Geophys. Res., 92, 1367313678, 1987.

Newell, P. T., and C. I. Meng, Ion acceleration at the equatorward edge of the cusp: Low altitude observations of patchy merging, Geophys. Res. Lett, 18, 1829-1832, 1991.

Newell, P.T.,C.-I. Meng, D.G. Sibeck, and R. Lepping, Some low-altitude cusp dependencies on the interplanetary magnetic field, J. Geophys. Res., 94, 8921-8927, 1989.

Newell, P.T., W.J. Burke, C.-I. Meng, E.R. Sanchez, and M.E. Greenspan, Identification an observation of the plasma mantle at low altitude, J. Geophys. Res., 96, 35-45, 1991.

Newell, P.N., and D.G. Sibeck, $B_{y}$ fluctuations in the magnetosheath and azimuthal flow velocity transients in the dayside ionosphere, Geophys. Res. Lett., 20, 1719-1723, 1993.

Onsager, T.G., A quantitative model of magnetosheath plasma in the low-latitude boundary layer, cusp and mantle, in Physical Signatures of Magnetopause Boundary Layer Processes, edited by J. A. Holtet and A. Egeland, NATO ASI Ser. $C$, vol. 425, pp. 385-400, Kluwar, Dordrecht, The Netherlands, 1994.

Onsager, T.G., C.A. Kletzing, J.B. Austin, and H. MacKiernan, Model of magnetosheath plasma in the magnetosphere: Cusp and mantlc particles at low-altitudes, Geophys. Res. Lett., 20, 479-482, 1993.

Paschmann, G., The Earth's magnetopause, in Achievements of the International Magnetospheric Study, IMS, Eur. Space Agency Spec. Publ., SP-217, 53-64, 1984.

Paschmann, G., G. Haerendel, I. Papamastorakis, N. Sckopke, S. J. Bame, J. T. Gosling, and C.T. Russell, Plasma and magnetic field characteristics of magnetic flux transfer events, J. Geophys. Res., 87, 2159-2168, 1982.

Paschmann, G., I. Papamastorakis, W. Baumjohann, N. Sckopke, C.W. Carlson, B.U.Ö. Sonnerup, and H, Lühr, The magnetopause for large magnetic shear: AMPTE/IRM observations, J. Geophys. Res., 91, 11099-11115, 1986.
Phillips, J.L., S.J. Bame, R.C. Elphic, J.T. Gosling, M.F. Thomsen, and T.G. Onsager, Well-resolved observations by ISEE 2 of ion dispersion in the magnetospheric cusp, $J$. Geophys. Res., 98, 13,429-13,440, 1993.

Reiff, P. H., and J. G. Luhmann, Solar wind control of the polar cap voltage, in Solar Wind-Magnetosphere Coupling, edited Y. Kamide and J. A. Slavin, p. 453-476, Terra Scientifica, Tokyo, 1986.

Reiff, P. H., T. W. Hill, and J. L. Burch, Solar wind plasma injection at the dayside magnetospheric cusp, J. Geophys. Res., 82, 479-491, 1977.

Rijnbeek, R. P., S. W. H. Cowley, D. J. Southwood, and C. T. Russell, A survey of dayside flux transfer events observed by the ISEE 1 and 2 magnetomcters, J. Geophys. Res., 89, 786-800, 1984.

Rijnbeek R. P., C. J. Farrugia, D. J. Southwood, M. W. Dunlop, W. A. C. Mier-Jedrejowicz, C. P. Chaloner, D. S. Hall, and M. F. Smith, A magnetic boundary signature within Clux transfer events, Planet. Space Sci., 35, 871-878, 1987.

Rosenbauer, H., H. Gruenwaldt, M.D. Montgomery, G. Paschmann, and N. Skopke, HEOS-2 plasma observations in the distant polar magnetosphere: The plasma mantle, $J$. Geophys. Res., 80, 2723-2737, 1975.

Russell, C. T., and R. C. Elphic, Initial ISEE magnetometer results: Magnetopause observations, Space. Sci. Rev., 22, 681-715, 1978.

Russell, C. T., and R. C. Elphic, ISEE observations of flux transfer events at the dayside magnetopause, Geophys. Res. Lett., 6, 33-36, 1979.

Sanchez, E.R., and G.L. Siscoe, IMP 8 magnetotail bound ary crossings: a test of the MHD models for an open magnetosphere, J. Geophys. Res., 95, 20,771-20,779, 1990.

Sanchez, E.R., G.L. Siscoe, J.T. Gosling, E.W. Hones Jr., and R.P. Lepping, Observations of rotational discontinuity slow expansion fan structure of the magnetotail boundary, $J$. Geophys. Res., 95, 61-73, 1990.

Scholer, M., Magnetic flux transfer at the magnetopause based on single $X$-line bursty reconnection, Geophys. Res. Lett., 15, 291-294, 1988.

Scholer, M., Asymmetric time-dependent and stationary magnetic reconnection at the dayside magnetopause, $J$. Geophys. Res., 94, 15099-15111, 1989.

Semenov, V.S., I.V. Kubyshkin, H.K. Biernat, M.F. Heyn, R.P. Rijnbeek, B.P. Besser, and C.J. Farrugia, Flux transfer events interpreted in terms of a generalized model for Petschek-type reconnection, Adv. Space, Res., 11, (9),25-28, 1991 a.

Semenov, V.S., N.V. Yerkayev, and M.F. Kheyn, Nonstationary Petschek reconnection. convective zone, Geomagn. Aeron., 31, 176-180, 1991b.

Semenov, V.S., I.V. Kubyshkin, V.V. Lebedeva, R.P. Rijnbeek, M.F. Heyn, H.K. Biernat, and C.J. Farrugia, A comparison and review of ready-state and time-varying reconnection, Planet. Space Sci., 40, 63-87, 1992 a.

Semenov, V.S., I.V. Kubyshkin, V.V. Lebedeva, M.V. Sidneva, H.K. Biernat, M.F. Heyn, B.P. Besser, and R.P. Rijnbeek, Time-dependent localized reconnection of skewed magnetic fields, J. Geophys. Res., 97, 4251-4263, $1992 \mathrm{~b}$.

Sibeck, D.G., Transient events in the outer magnetosphere: boundary waves or flux transfer events?, J. Geophys. Res., 97, 4009-4026, 1992.

Sibeck, D.G., Transient magnetic field signatures at high latitudes, J. Geophys. Res., 98, 243-256, 1993.

Sibeck D.G., and M.F. Smith, Magnetospheric plasma flows associated with boundary waves and flux transfer events, Geophys. Res. Lett., 19, 1903-1906, 1992.

Smith, M. F., and M. Lockwood, The pulsating cusp, Geophys. Res. Lett., 17, 1069-1072, 1990.

Smith, M.F., and C.J. Owen, Temperature anisotropies in a 
magnetospheric FTE, Geophys. Res. Lett., 19, 1907-1910, 1992.

Smith, M.F., and D.J. Rodgers, Ion distributions at the dayside magnetopause, J. Geophys. Res., 96, 11,617-11,624, 1991.

Smith, M.F., M. Lockwood, and S.W.H. Cowley, The statistical cusp: A flux transfer event model, Planet. Space Sci., 40, 1251-1268, 1992.

Sonnerup, B.U.Ö., I. Papamastorakis, G. Paschmann, and H. Lühr, The magnetopause for large magnetic shear: Analysis of convection electric fields from AMPTE/IRM, J. Geophys. Res., 95, 10,541-10,557, 1990.

Southwood, D. J., C. J. Farrugia, and M. A. Saunders, What are flux transfer events?, Planet. Space Sci., 36, 503-508, 1988.
Thomsen, M. F., J. A. Stansberry, S. J. Bame, S. A. Fuselier, and J. T. Gosling, Ion and electron velocity distributions within flux transfer events, J. Geophys. Res., 92, 12127-12,136, 1987.

Tsyganenko, N.A., Global quantitative models of the geomagnetic field in the cislunar magnetosphere for different disturbance levels, Planet. Space Sci., 35, 1347-1358, 1987.

C. J. Davis and M. Lockwood, Rutherford Appleton Laboratory, Chilton, Didcot, OX11 0QX, United Kingdom. (e-mail: mike@eiscat.ag.rl.ac.uk)

(Received January 31, 1994; revised August 18, 1994; accepted August 22, 1994.) 